\title{
How to Measure Success in University Led Engineering Outreach Programs for Elementary School Children
}

\author{
M.C. Scherer, OCT \\ Manager of Engineering Outreach \\ University of Waterloo \\ Faculty of Engineering \\ mscherer@uwaterloo.ca
}

\author{
Dr. M.A. Wells, P.Eng \\ Associate Dean of Engineering Outreach \\ University of Waterloo \\ Faculty of Engineering \\ mawells@uwaterloo.ca
}

\begin{abstract}
Over the past twenty years, the University of Waterloo's Faculty of Engineering has been a strong supporter of engineering outreach programs for youth in the elementary school group age (6-14). This outreach has primarily occurred via the Engineering Science Quest (ESQ) program which is mainly student staffed. To date the program has reached over 20,000 youth in its camps, and have exposed countless others through school workshops and community involvement. A question that often arises in this program is how to define and measure success and what metrics to use. Acknowledging that the traditional quantitative definitions of engineering success, such as long term data collection to measure outcomes, are very difficult to obtain, new metrics have to be developed that support the anecdotal evidence of the programs. These metrics need to reflect the limitations imposed by both time and external factors that can affect the final results. It is concluded that at different points in the growth of an outreach program, different metrics for measuring success should be used. In addition, the overall objective and goals of the program need to be initially well defined to be able to obtain the data required to measure success.
\end{abstract}

\section{Background}

Last year, over 225,000 Canadian youth in over 450 communities nationwide experienced hands-on programming related to science and engineering by one of close to 30 college and university based outreach organizations across Canada [1]. These organizations deliver science, engineering and technology workshops, summer day camps, clubs and other community outreach initiatives for youth. Science, engineering and technology based outreach programs have been in existence for the past twenty years in Canada and have become a regular choice for parents as a summer camp experience or to help teachers augment their curriculum materials through the use of hands-on workshops. Many of these programs are enrichment programs aimed at attracting the brightest high school students to consider studying engineering and science at their universities. Hence one measure of success for these programs is their ability to recruit top level students both locally and across the country.

Mandatory youth outreach components are also embedded in many of the Ontario government research funds. For example, the Ontario Research Fund grants and Ontario Early Researcher Awards both have a mandatory component of youth outreach that must be detailed as part of the research grant proposal. The motivation for this is to expose students (predominantly in secondary schools) to current state of the art research occurring at universities and industry [2].

Another motivating factor for why an emphasis of outreach in science and engineering is important, relates to how dependent our society has become on technology and how embedded or hidden this technology is in our everyday lives. By exposing students to the important role, science, engineering and technology play, this will make certain that students are excited and understand the value of learning about these subjects as they graduate from both elementary and high school. A key constituency which does not seem to have received as much attention in terms of college and university outreach is elementary school age children. Part of the reason for this is that elementary school children are so far away from going to university that the goal of the outreach is less about recruitment and more about exposure to science and engineering. This lack of a tie to recruitment often makes the motivations for doing this outreach less clear. However, elementary school children can benefit immensely from exposure to 
university led research and this will help then to develop a perspective on the current boundaries of knowledge in different fields.

In the current education system, elementary school teachers are often asked to be a jack of all trades, as they are responsible for multiple aspects of a child's educational development. Being a jack of all trades though usually means that you are a master of none. This lack of mastery is often most evident when looking at how science is taught in the elementary school. The question of science confidence is addressed by the recent Trends in International Mathematics and Science Study (TIMSS) which shows a discrepancy in our elementary science teachers; only $54 \%$ of grade eight science teachers surveyed in Ontario reported feeling 'very well' prepared to teach science. In addition, only a reported $20 \%$ feel comfortable asking students to design or plan their own experiments in class where the nature and outcome of the experiment is less predictable [3].

Ontario teacher's who are qualified to instruct at the grade 4 to 10 level are asked to have at minimum one 'teachable' (area of expertise). The Ontario College of Teachers reports that only $19 \%$ of new members (from 1998 to 2008) who are qualified to teach this grade range have science as their expertise [4].

Elementary school teachers who do not have a strong background in science or engineering are often unsure about their abilities. As a result, they lack the confidence needed to teach lessons that are heavily based on discovery. Instead of risking failure in front of the class, they focus on memorization or a less interactive approach to science. The TIMSS results supports this observation, stating that less than half of grade 8 teachers in Ontario engage their class regularly with hands-on experiments [3]. Another confounding factor is that teachers usually have little engineering background or confidence to apply scientific and mathematical principles to other problems they are studying. Hence students can get a negative impression of the usefulness of science, math and engineering in their everyday lives.

Beside the ability to physically engage in science, another important aspect of scientific education is the level of scientific and technology literacy in our youth. Science literacy is no longer "simply being informed about new advances, for example in medicine and technology" [5] but "science literacy is the occupational capacity to apply information in an appropriate contest, to analyze information, to synthesize information from various sources or on various topics, and evaluate information to determine the best course of action. Essentially, being scientifically literate in the 21 st century means understanding the nature of science as a process that helps us discriminate between what is real or likely and what is not" [5]. In this context, it also becomes important for students in science and engineering to be able to effectively communicate with non-technical audiences in a way that makes the information meaningful and relevant.

\section{University of Waterloo's Engineering Science Quest (ESQ) Program}

At the University of Waterloo, The Engineering Science Quest (ESQ) program has been working for 20 years to expose elementary school children to hands-on science and engineering. The goals of the program are to excite students about science, engineering and technology and show them through hands-on and practical activities how this knowledge can be applied to solve real world problems. A secondary goal of ESQ is to improve the engineering, technological and scientific literacy amongst the elementary youth. All activities are designed to complement the current Ontario elementary curriculum.

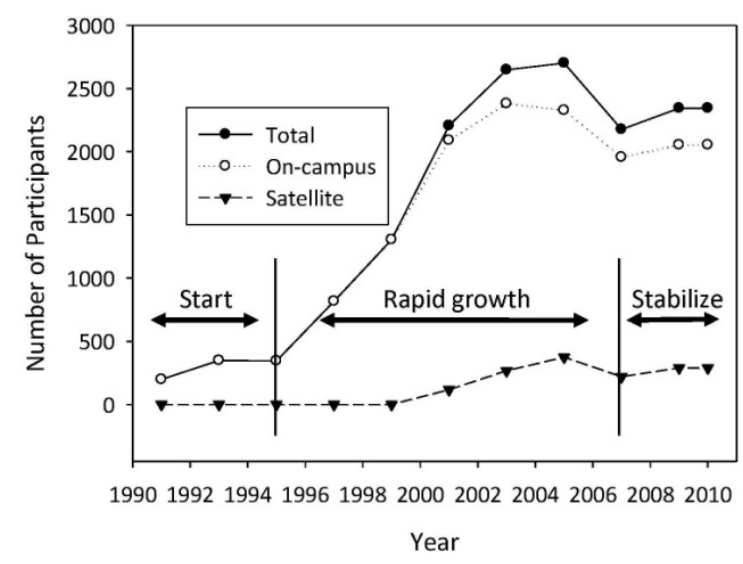

Figure 1. Growth in ESQ outreach program over time

In its first summer (1991), ESQ reached a combined 199 students in grades 5 and 6 . By 1993, the program saw a $50 \%$ increase in size and expanded to offer programs for youth in grades 5 through 8 . By 1997, the program was offering programming for youth in grades 3 through 12 and had increased enrollment to 800 participants. In 2001, the program started to run weeks of camp in various aboriginal and rural locations in southwestern Ontario. The program continued to grow, exceeding its maximum size in 2005 with 2,800 participants and offering multiple camps for youth in grades 1 to 12. Due to finical and space constraints the program has been scaled back to 
accepting on average 2,200 participants a year, and operating both on the Waterloo campus, and various satellite locations in south-western Ontario. During the summer of 2009, over 115 one week sessions of camp were held. Figure 1 shows the history of the ESQ operation as well as the number of youth reached.

Activities for the ESQ summer camps are developed and delivered by University students, the majority of which study science and engineering. Senior and junior high schools students also help to run the camps and serve as role models for the elementary school campers. In turn, the University students mentor and coach the high school students.

Typically, University instructors develop the week of camp activities around a central theme (e.g., camping, space exploration, the Olympics etc.). Hands-on activities within the theme related to specific disciplines in science and engineering are then developed and integrated across the theme area. Figure 2 shows the anatomy of an ESQ camp week with the relative proportions of science, engineering and design. The learning in the camp is focused on: 1) hands-on activities and 2) knowledge integration around a central theme. In each camp an emphasis is also placed on exposing children to innovation by linking creativity, and in older camps elements of entrepreneurship, with the activities.

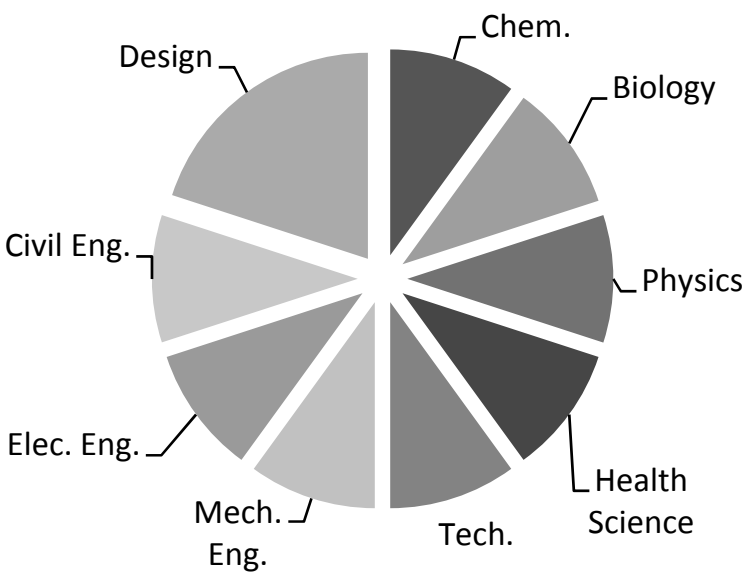

Figure 2. Anatomy of an ESQ summer camp

In addition to the above camps, the following yearround programming is currently being offered:

- In-School workshops (45 to $75 \mathrm{~min}$ experiential lessons to compliment the program)

- Birthday party programming

- Open house/community event programming

\section{Measuring Success}

The literature on outreach programs in science and engineering is vast. However, there is little, information on assessment of K-12 engineering outreach programs [6]. A review of these programs describes several different models of outreach ranging from summer camps with hands-on components through to one-on-one mentoring with engineering and science students [7]. The review notes that it has become clear to educators that students need to be introduced to engineering at an early age, and that K12 teacher's need assistance from engineers and engineering educators. It further states that all successful engineering outreach programs have a "do" or hands-on component; hearing or reading about engineers or engineering is not enough. However, it is difficult to assess the effectiveness of the different models as no standardized and credible way of measuring or assessing the programs is available.

Since the age group for ESQ programming is primarily elementary school age children, not all children who attend an ESQ summer camp or inschool workshop will study science or engineering at the university level. Hence it becomes more problematic, to measure success of the ESQ outreach program based on recruitment of students into engineering and science programs at university.

Developing effective metrics for program success can prove to be a challenge as outreach programs like ESQ grow. The simplest measurement for programs in the early stages of development is often demand for the program and how quickly programs fill. In the case of ESQ, after twenty years, the growth has stabilized, and now the organization finds itself in the situation of finding new and effective metrics to show success to interested external groups, such as program funders and the supporting faculties of the program.

Effective metrics should reflect the vision, mission and strategic goals of the program. These need to be clearly understood by both the program organizers and the external supporter of the organization. The primary mission of ESQ is to increase engineering and science literacy, through engaging participants with hands-on activities. A secondary goal is to demystify the university and make it appear as an accessible/achievable educational end point for the participants.

During the process of collecting metrics, a variety of anecdotal evidence may be presented through comments and program review. Anecdotal evidence should not be dismissed, as it provides stories and narratives for the program, which puts its success in perspective. The statistics that are generated from 
metrics tell one story, but this evidence tells the other important story, the human story.

\subsection{Long-term Metrics}

Long-term metrics are the most desired metric by both program funders and university supporters. Often the question heard to be asked is 'how many participants go on to attend school at our institution?' A valid question, but one that is extremely hard to effectively track and can take upwards of ten to fifteen years to start to get reasonable levels of data. The validity or directly correlating ESQ to a student's decision to study science or engineering at university is also problematic as many other influencing factors in the child's life may have played an equal or more important role e.g. parents, teachers and peers.

\subsection{Short-term Metrics}

Short-term metrics are generally contained to judging the success of the program immediately after its conclusion. There are a variety of short term metrics that can be used; with the most common being participation surveys targeted at both parents and the program participants. These surveys should be quick to fill out, and make use of scaling questions, and questions designed so that the results can be used to implement appropriate changes in the program for the following year.

Parent surveys provide some more insight, as the program will be often compared to other programs that the child has been in that year. Including an openended comment box, will generate more constructive feedback, and anecdotes concerning the program. Running these surveys at the end of each weekly session generates a variety of feedback that can be used to improve the camp for the following weeks in the summer and beyond.

From experience, post-camper surveys tend to be positive overall, and are more of a reflection on the past day's activities then the week as a whole. If the last experience they had was overly positive, then the survey will be glowing, similarly the opposite results happen when the last experience was negative.

This year, ESQ will be running modified pre and post camper surveys to try and derive more useful information on the effectiveness of the camp. The pre and post camp surveys will be the same, asking a variety of programming questions (e.g. "What are you looking forward to?" "What was the best thing about this past week?") and theory questions ("What is an atom?"). The programming questions will be used as typical camper survey questions, to help gauge relevancy of the program. The theory questions will be used to judge short-term retention of the science and engineering concepts taught. The theory questions will be marked out of a total of two, with one mark award for partial answer, and two for a satisfactory answer. Activities addressing this theory will be held earlier in the week. Comparing the group's total pre and post score on this theory will provide data on the program's success in its teaching methods.

It is important when constructing these surveys that theory questions are kept to a minimum. The surveys should not resemble a test, or give the illusion that the participants are in school instead of a camp setting.

\subsection{Exposure Metrics}

Metrics of exposure provide the best bridge between short-term metrics and long-term. They directly address the goal of the program, and can be used to draw some historical conclusions about the potential impact of the program.

By running a variety of programming beyond the summer camps, such as workshops and community events, many barriers to participation normally encountered, such as registration fees, are eliminated. This variety of programming also provides exposure to diverse (underrepresented) audiences It is further reasoned, that as long at the activities are of a high caliber, the greater the amount of exposure, the greater the chance is to have a positive increase in science and technology literacy.

Table 1. Instructional time with different participant groups for ESQ programming in 2009

\begin{tabular}{|c|c|c|}
\hline Event Type & No. Attended & Total Hours \\
\hline Workshops & 7.535 & 9,400 \\
\hline $\begin{array}{c}\text { Summer } \\
\text { Camps }\end{array}$ & 2,442 & 73,300 \\
\hline $\begin{array}{c}\text { March } \\
\text { Break Camp }\end{array}$ & 352 & 10,600 \\
\hline Clubs & 205 & 700 \\
\hline $\begin{array}{c}\text { Birthday } \\
\text { Parties }\end{array}$ & 345 & 700 \\
\hline $\begin{array}{c}\text { Community } \\
\text { Events }\end{array}$ & 10,620 & 1,700 \\
\hline TOTAL & 21,499 & 96,400 \\
\hline
\end{tabular}

Simply counting the number of people who attend the event can give an artificially high appearance of success. By converting these numbers to represent face-to-face time (instructional time), a comparison metric can be developed and used to compare the overall program from year to year. Table 1 indicates face-to-face time for ESQ in 2009 based on its range 
of programs. While saying ESQ exposed over 20,000 youth to engineering and science in 2009 is an impressive result, saying that they spent $96,000+$ hours of face-to-face instructional time puts that number into context, eliminating potential discrepancies attached to the participant reached number. For example, if enrollment in the camps went down, but larger community events were attended, ESQ may have a higher reported number reached, but possibly a lower face-to-face time.

\section{Discussion}

While the primary participants of the ESQ programs are elementary school participants, others can benefit immensely from the program, such as the science and engineering students who develop and deliver the content. A secondary impact of our outreach program that can be measured is to the ability or change in ability of ESQ instructors to communicate technical subjects effectively with a non-technical audience. The short term metrics used for camper participation does give some potential insight into the current staff ability, but is not critical enough of instructional style to yield meaningful results. This can be done via observation and assessment.

Another area of future growth for ESQ is to create programs that have the goal of increasing confidence levels in pure and applied sciences amongst current and future elementary school teachers. Such programs have great potential for positive long-term impact as these teachers are the primary source for science instruction and encouragement in the elementary student's life. By focusing on teachers, it is also easier to generate longer-term metrics of success as they are in a more stable point in their academic life - simply put, they have less outside sources which can influence their science confidence and literacy levels. Metrics for teachers can also be quantitative in terms of how they change their teaching style to be more inquiry based versus rote memorization as well as their ability to introduce applied problems and use more hands-on activities.

\section{Conclusion}

Our primary goal as educators should be to foster a nation of life-long learners. "If the goal of 'understanding for all' is to be achieved, then the science education community must recognize that understanding in science develops through practice and that we must design classrooms where realistic practice can happen." [8]

ESQ was created to address this need, and has grown beyond what people expected it to be-a small summer camp program. This growth and stronger emphasis on program quality/sustainability brought a renewed need for metrics to show its success. Through the past year of exploring various options, ESQ has come to the conclusion that there is no simple "catchall' method to adequately show its success.

Long-term metrics have a high cost (financial and in personnel time) and will likely yield very little data that is useful for the improvement of the program. In particular it would be difficult to isolate the effect ESQ had compared to other influences in the person's life. As ESQ evolves and changes its own programs and instructors it would be difficult to pinpoint exact causes and effects. Factoring in the aforementioned high rate of annual change in programs like ESQ, it becomes clear that the strongest system to be used is a combination of short-term and exposure metrics. These two provide the ability to inform decisions in programming direction for the following year, and with the use of the face-to-face metric, a historic context that can be called on when needed to help visualize long-term exposure rates.

The organizers must fully understand what the programs goals are, as this is paramount in the creation of meaningful metrics.

A common set of metrics should be adopted and decided amongst partner organizations that would help compare all our work on a provincial/national level. But with each program uniquely structured and supported, finding these commonalities will prove to be a challenge. The best metric to use for comparison would be to take the total face-to-face time, and divide it by the year round staff size, or by the work hours put in to achieve it. Any comparison of metrics should be taken in perspective of the uniqueness of each program and not used to rate one program over another-all programs have the same set of fundamental goals, it just happens that success can appear radically different between each program.

\section{References}

[1] Actua, "Make Friends With Science: Annual Report 2008", 2008. [Online], Available: http://actua.ca/files/documents/ actua_annual_report_2007_08.pdf. [Accessed 17 May 2010]

[2] Govt. of Ontario, "Youth Science and Technology Outreach Program Overview", 27 April 2010. [Online]. Available:

http://www.mri.gov.on.ca/english/programs/ystop/ program.asp. [Accessed: 13 May 2010]. 
[3] Education Quality and Accountability Office, "Trends in International Mathematics and Science Study (TIMSS), 2007", December 2008 [Online]. http://www.eqao.com/pdf_e/08/

TIMSS_Ontario_Report_2007.pdf. [Accessed: 13 May 2010].

[4] Ontario College of Teachers, "Historical Statistics", 2008 [Online], http://www.oct.ca/annual_report/2008/en/ stats_downloads.html [Accessed: $1 \overline{7}$ May 2010].

[5] “The Importance of Science Literacy”, 14 May 2008. [Online]. Available: http://sciedsociety.blogspot.com/2008/ 05/importance-of-scientific-literacy.html. [Accessed: 13 May 2010].
[6] S.J. Poole, J.L. deGrazia, and J.F. Sullivan, "Assessing K-12 Pre-Engineering Outreach Programs", ASEE/IEEE Frontiers in Education Conference, San Juan, Puerto Rico, 10 November 1999.

[7] A.T. Jeffers, A.G. Safferman and S.I. Safferman, "Understanding K-12 Engineering Outreach Programs", Journal Of Professional Issues in Engineering Education and Practice, ASCE, April 2004, pp. 95-108.

[8] J. Cartier, C. Passmore and J. Stewart, "The Practice of Science", November 2001. [Online] Available: http://www.wceruw.org/news/coverStories/

practice_of_science.php. [Accessed: 13 May 2010] 